\title{
Design of Standardized Breeding System for Rabbits Based on Internet of Things
}

\author{
Hong-Jun GU ${ }^{1}$, a , Ji LI ${ }^{1}$, Zhi GU², Dong-Bo REN ${ }^{1}$, He GONG ${ }^{1}$, Jian $\mathrm{LI}^{1}$, Shi-Jun \\ $\mathrm{LI}^{1, \mathrm{~b}}$ \\ ${ }^{1}$ Jilin Agricultural University, Changchun 130118, Jilin, China \\ ${ }^{2}$ Shenyang Funing Rabbit Industry CO., LTD \\ aghj_dennis@163.com, bisj0883@sina.com
}

Keywords: IOT, standardized breeding, rabbit, integrated service management platform.

\begin{abstract}
There exist issues of fast environmental degradation, poor intelligence, and low management efficiency with the improvement of breeding rabbit scale. This paper presents the standardization breeding system of rabbit based on internet of things (IOT). This project realizes automatic precise feeding, growth environment monitoring and control, and integrated service management platform. This system can meet the needs of the rabbit growth environment, save resources and labor, reduce disease incidence, improve the quality of rabbit meat and fur, which has important guiding significance to large scale production of rabbit in the future.
\end{abstract}

\section{Introduction}

In recent years, the rabbit production has been paid widely attention throughout the world. Some international organizations and experts suggest developing rabbit production for many times, and making it one of the human animal protein sources [1]. The breeding industry has realized the full automation in many developed countries. Modern equipments are used into the rabbit breeding in France, and the motor drive the conveyor to distribute the rabbit food automatically [2]. In the hot regions of America appeared a new kind of 'underground warren', which was built underground, warm in winter and cool in summer [3]. And America's warrens are equipped with air conditionings. In Japan, expert system has been used in the rabbit breeding. This system can monitor and control the environment automatically, and diagnose the rabbit disease. Foreign modern rabbit breeding farmers adopt factory production mode [4]. The enclosed warren can control the environmental temperature and humidify automatically, and epidemic prevention measures are very modern. The system can calculate and distribute the ingredients, feed food and water, and clean up the feces by a computer [5]. In the good management mode, rabbit can grow and breed evenly in four seasons. Abroad in recent years, modern commodity warren appeared a new technology of 'impending raising rabbit'. Rabbit cage is hanged on the ceiling bracket, and the height depends on convenient management operation [6]. This way has a good ventilated effect which is suitable for rabbit habit and has high technical content.

There are many rabbit literatures in China, but the reports of related intelligent equipment and management system are rare. In 2010 Zhang Jiaquan in Jilin university wrote a paper about automatic feeding food and water, and lighting device in the warren, which is the early domestic literature on designing modern equipment [7]. In 2014 Wei Xuyang in Southwest university designed warren information management system [8]. In 2015 Ye Yun in South China Agricultural university designed large-scale production warren management system, which makes baby rabbit survival rate increased by $5.15 \%$, and lower mortality [9]. At present, the domestic rabbit breeding develops toward large-scale and scientific breeding direction.

\section{Overall System Framework}

The overall system framework is shown in Fig .1, system nodes collect environmental parameters, including video information, and conveys them to the integrated service management platform (ISMP) 
via wireless sensor network, mobile network or internet. ISMP saves the environmental parameters and sends the data and information to the mobiles and computers of administrators. The administrator can give the corresponding commands to the control and feeding equipment. ISMP can control the related devices automatically under the absence of the administrator management.

The system can be divided into three sections: automatic precise feeding, growth environmental monitoring and control, and integrated information service management platform.

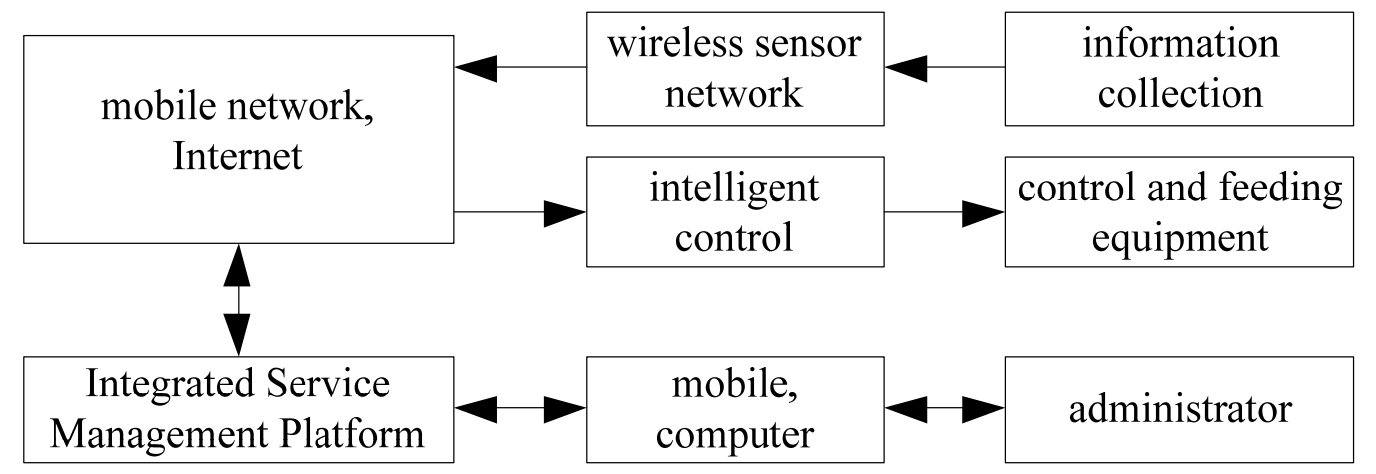

Fig. 1 The overall system framework

\section{Automatic Precise Feeding}

Automatic precise feeding includes quantitative food and regular watering. As shown in Fig .1, the valve can be opened to a gap depending on the intake food, and then the conveyor can be driven by a motor to distribute the rabbit food. When the conveyor stops, the slide is driven to some distance, and the gaps can appear. Every rabbit has a gap, which ensures the same dose. The whole process is carried out automatically. Fig .3 shows the real process of rabbit feeding. The left food can be weighed and the data can be send to ISMP and administrators, by which whether rabbits have diseases can be judged.
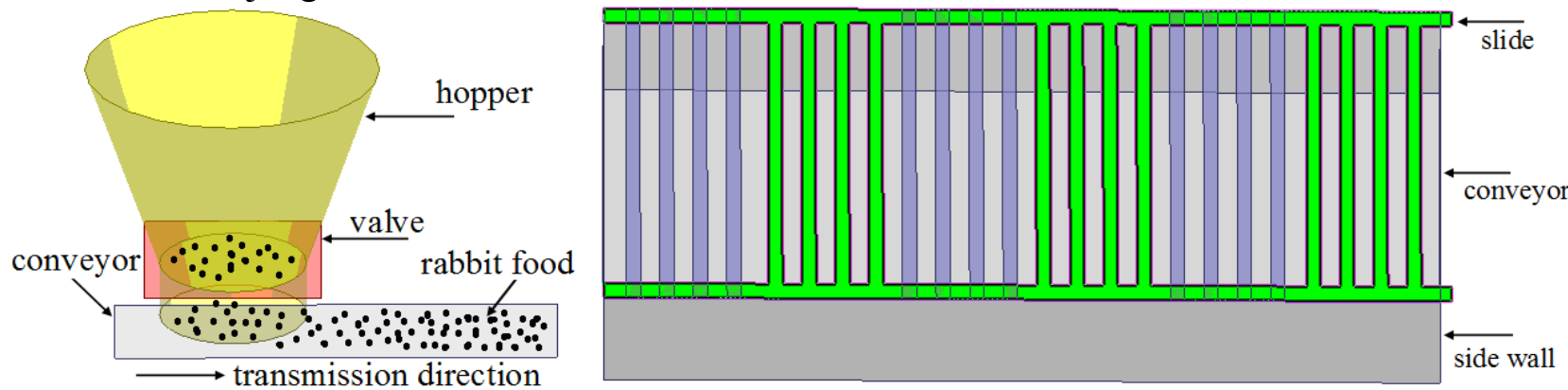

Fig. 2 Automatic feeding-food device

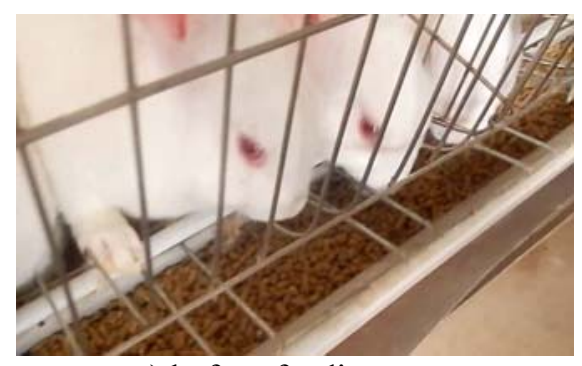

a) before feeding

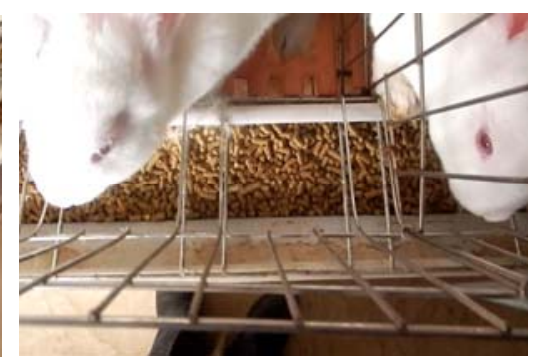

b) feeding

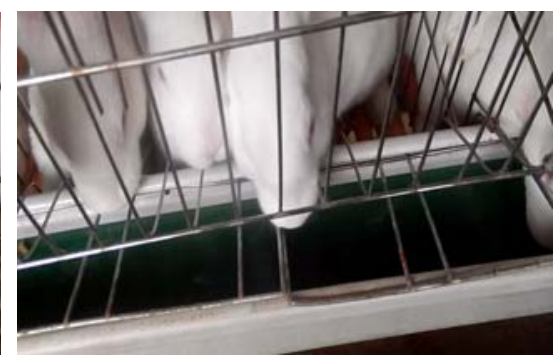

c) after feeding

Fig. 3 Pictures of rabbit feeding

Regular watering may be realized by timers. The administrators can modify the rabbit watering time. The system controls a pump to inject water into the pipes at the regular time. Fig .4 shows the picture of rabbit regular watering.

Quantitative food and regular watering ensure that the rabbits grow at the same speed, gastrointestinal disease incidence decreases sharply, survival rate increases to some extent, and quality of rabbit meat and fur get better. 


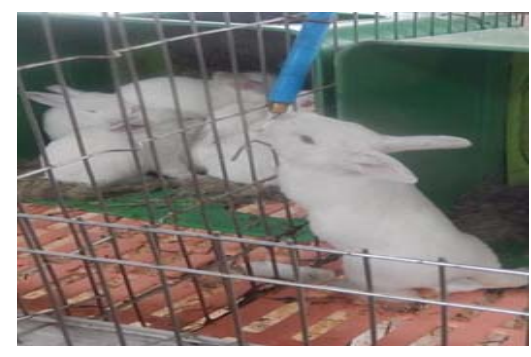

Fig. 4 Pictures of regular watering

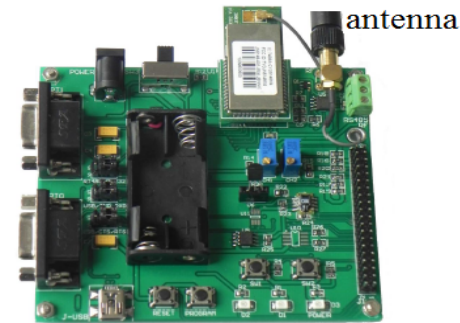

Fig. 5 Node diagram

\section{Growth Environment Monitoring and Control}

There are several information acquisition nodes integrated in many sensors and cameras in the rabbitry. Fig .5 shows one node diagram with two $1.5 \mathrm{~V}$ battery power supply, in which many sensors are integrated. These nodes can collect environmental parameters of air temperature and humidity, $\mathrm{CO}_{2}$ concentration, light intensity and ammonia concentration, which can be sent to ISMP through the wireless sensor network. According to the requirements of rabbit growth, the system controls ventilation, lighting and heating, automatically to adjust the environment parameters. Cameras can get the vedio information, which can be sent to ISMP, the user can view the conditions of the rabbits via mobiles or computers at any time. So the system ensures rabbits grow in the optimal environment, reduce the disease incidence.

Each node uses ZigBee technology as the core. In this design, the chip CC2530 is applicable, and its schematic diagram is shown in Fig .6.

Rabbit dung is regularly washed by water and transported to the big manure pit for crop fertilizer. And the following is to open the windows and electric fans for timely ventilation.
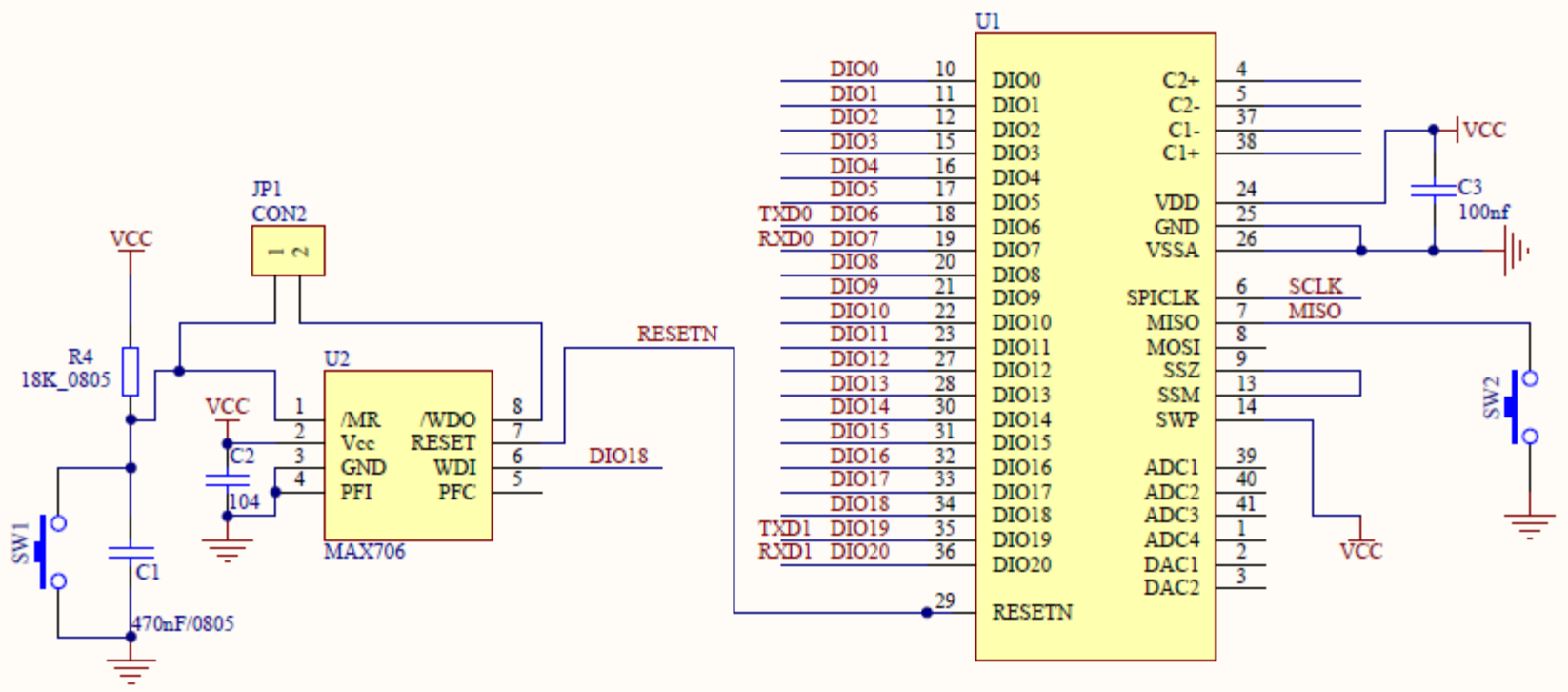

Fig. 6 Schematic diagram of minimum system board

\section{Integrated Service Management Platform}

ISMP is also an expert decision support system, using ASP.Net development framework and B/S architecture design. All the rabbit information is input into the system. According to the rabbit conditions at every stage, this system can make a comprehensive analysis and judgment, and give the related commands to administrate the epidemic prevention, breeding, feeding. When the warren conditions are abnormal, ISMP launches the alarm devices and sends the alarm message to the administrators.

\section{Conclusions}

This paper designs a standardization breeding system of rabbit based on IOT. This system includes three parts: automatic precise feeding, growth environment monitoring and control, and integrated 
service management platform. The first task is to design an automatic precise feeding system which saves a lot of labor and decrease rabbit food spoiled. And the second one is design growth environment monitoring and control system which ensures the good sanitary conditions rabbits need. The third one is to design ISMP which can save, analyze and convey much related data of rabbits, and give the suitable control commands. This subject solves the issues of inefficiency, fast environmental degradation, and easy disease spread in the warren. This system can improve the production efficiency and economic benefit for future scale warren.

\section{Acknowledgments}

The authors wish to express their gratitude to the projects: Design of Standardized Breeding System for Rabbits Based on Internet of Things from Education Department of Jilin Province (No. 185 ), Jilin Province Economic Structural Adjustment Leading Fund Special Project (No. 2014Y108) and Changchun City Science and Technology Plan Project (No. 14nk029, No. 13KG71), Key Tackling Item of Jilin Province Science \& Technology Department (No. 20140204045NY), Jilin Province Science \& Technology Department Project (No. 20150204058NY, No. 20140204045NY) for their generous support of this work.

\section{References}

[1] GUO Laixiao. The Design and Realization of Intelligent Breeding System for Livestock-Poultry Based on 3G and IOT[D]. Zhenjiang: Jiangsu University, 2014, in Chinese.

[2] Hwang J, Yoe H. Study of the ubiquitous hog farm system using wireless sensor networks for environmental monitoring and facilities control[J]. Sensors, 2010, 10(12): 10752-10777.

[3] YIN Ling, LIU Caixing, HONG Tiansheng, et al. Design of system for monitoring dairy cattle's behavioral features based on wireless sensor networks[J]. Transactions of the Chinese Society of Agricultural Engineering (Transactions of the CSAE), 2010, 26(3): 203-208, in Chinese.

[4] WANG Ling, ZOU Xiaoyu, LIU Siyao, et al. Development of handheld terminal for sheep breeding information management based on RFID and ZigBee[J]. Transactions of the Chinese Society for Agricultural Machinery, 2014, 45(9): 247-253, in Chinese.

[5] HUANG Jianqing, WANG Weixing, JIANG Sheng, et al. Development and test of aquacultural water quality monitoring system based on wireless sensor network $[\mathrm{J}]$. Transactions of the Chinese Society of Agricultural Engineering (Transactions of the CSAE), 2013, 29(4): 183-190, in Chinese.

[6] Quwaider M Q, Daigle C L, Biswas S K, et al. Development of a wireless body-mounted sensor to monitor location and activity of laying hens in a non-cage housing system[J]. Transactions of the ASABE, 2010, 53(5): 1705-1713.

[7] ZHANG Jiaquan, WU Qingyan, FENG Yi, et al. Design of automatic feeding, watering and lighting device for rabbit [J]. Journal of Northeast Agricultural University, 2010, 41(9): 128-132, in Chinese.

[8] WEI Xuyang, WU Chunming, ZOU Xitao, et al. Design and Implementation of Information Management System in Rabbit Farms [J]. Agriculture Network Information, 2014, 2: 25-28, in Chinese.

[9] YE Yun, HU Mingyue, ZHAO Xiaojuan, et al. Design and implementation of production supervising system for large scale rabbit farm[J]. Transactions of the Chinese Society of Agricultural Engineering, 2015, 31(22): 229-234, in Chinese. 